\title{
Clinical Impact of after-consult clinic blood pressure: comparison with automated office blood pressure
}

\author{
Cheol Ho Lee ${ }^{1}$, Ji Hun Ahn², Joon Ha Ryu and Woong Gil Choi ${ }^{2 *}$
}

\begin{abstract}
Background: It is most important to measure blood pressure (BP) exactly in treating hypertension. Recent recommendations for diagnosing hypertension clearly acknowledge that an increase in BP attributable to the "whitecoat response" is frequently associated with manual BP recordings performed in community-based practice. However, there was no data about after-consult (AC) BP that could reduce whitecoat effect. So we evaluated before-consult (BC) and $A C$ routine clinic $B P$ and research based automated office blood pressure (AOBP) measured.

Methods: The study population consisted of 82 consecutive patients with hypertension between April 2019 and December 2019. We measured routine clinic BP and AOBP before and after see a doctor, respectively. Seated blood pressure and pulse are measured at each time after a rest period using an automated device as it offers reduced potential for observer biases. AOBP was measured and measuring BP 3 times un-observed. We compared each BP parameter for identifying exact resting BP state.

Results: There was significant difference between BC and AC systolic BP $(135.37 \pm 16.90$ vs. $131.95 \pm 16.40 \mathrm{mmHg}$, $p=0.015)$. However there was no difference in the BC and AC diastolic blood pressure (73.75 \pm 11.85 vs. $74.42 \pm$ $11.71 \mathrm{mmHg}, p=0.415$ ). In the AOBP comparison, there was also significant difference (BC systolic AOBP vs. AC systolic AOBP, $125.17 \pm 14.41$ vs. $122.98 \pm 14.09 \mathrm{mmHg}, p=0.006 ; B C$ diastolic $A B O B$ vs. AC diastolic AOBP, $71.99 \pm$ 10.49 vs. $70.99 \pm 9.83, p=0.038)$.
\end{abstract}

Conclusions: In our study, AC AOBP was most lowest representing resting state. Although AC BP was higher than $B C A O B P$, it might be used as alternative measurement for reducing whitecoat effect in the routine clinical practice.

Keywords: Blood pressure, Whitecoat, Hypertension

\footnotetext{
* Correspondence: gilll7@kku.ac.kr

${ }^{2}$ Internal medicine, School of Medicine, Konkuk University, 82,

Gugwon-dearo, Chungju, Chungbuk 27376 Chungju, South Korea

Full list of author information is available at the end of the article
}

(c) The Author(s). 2021 Open Access This article is licensed under a Creative Commons Attribution 4.0 International License, which permits use, sharing, adaptation, distribution and reproduction in any medium or format, as long as you give appropriate credit to the original author(s) and the source, provide a link to the Creative Commons licence, and indicate if changes were made. The images or other third party material in this article are included in the article's Creative Commons licence, unless indicated otherwise in a credit line to the material. If material is not included in the article's Creative Commons licence and your intended use is not permitted by statutory regulation or exceeds the permitted use, you will need to obtain permission directly from the copyright holder. To view a copy of this licence, visit http://creativecommons.org/licenses/by/4.0/. The Creative Commons Public Domain Dedication waiver (http://creativecommons.org/publicdomain/zero/1.0/) applies to the data made available in this article, unless otherwise stated in a credit line to the data. 


\section{Background}

The effect of blood pressure (BP) to cardiovascular disease is obvious [1]. It has been well known that early intensive BP control affect benefit that reduced long term mortality or target organ damages [2]. Therefore, it is important to recognize and minimize early vascular and organ damages.

There is no concern that method of BP measurement is basic and important step in the hypertensive patient management. Hypertension guidelines described precisely BP measurement dividing conventional office BP, unattended office BP, out of office BP, Home BP, and ambulatory BP $[3,4]$. Generally, values of measured BP in the doctor's office is still cornerstone of BP control and hypertension treatment and BP is usually measured before see a doctor.

However, an increase in BP attributable to the "white coat response" is frequently associated with manual office BP recordings performed in community-based practice [5-7]. So, we designed after-consult (AC) BP measurement. This would be reflected more comfortable, physically stable state of patient. However, there was no study whether AC BP is less variable and could reflect long-term prognosis or not.

We evaluated before-consult (BC) and $\mathrm{AC}$ clinic BP and research based automated office blood pressure (AOBP) measured.

\section{Methods}

\section{Study population}

Participants were required to meet all the following criteria: controlled hypertensive state with medication, older than 18 years, no medication change during recent 3 month. Detailed exclusion criteria are one or more of following below: patients with secondary hypertension, uncontrolled diabetes mellitus, chronic kidney disease needing dialysis, more 2 times of AST/ALT, drug sensitivity, atrial fibrillation or uncontrolled arrhythmia. All participants provided written informed consent.
All major classes of antihypertensive agents were included in the formulary and we did not change medications during follow up period as possible as. Study investigators could also prescribe other antihypertensive medications.

\section{Blood pressure measurement}

We measured three BP: office BP, AOBP and $24 \mathrm{~h}$ ambulatory $\mathrm{BP}(\mathrm{ABP})$. For office BP, an initial single observed $\mathrm{BP}$ measurement with non-invasive oscillometric system (OMRON HBP 1300, Japan) was performed after 5 min of quiet rest period using appropriate cuff size for mid-arm circumference, seated in chair, cuff at mid sternal level, arm supported on a flat surface, feet flat on the floor, with no conversation during the measurement.

AOBP was performed with another device (OMRON HEM-907XL, Japan) with the technique noted above but with the patient entirely alone in the exam room resting quietly and mean of three blood-pressure measurements was reported.

Twenty-four-hour ABP was monitored using validated oscillometric arm devices (TM-2430, A\&D Company, Tokyo, Japan). Measurements were performed at 15$30 \mathrm{~min}$ intervals for $24 \mathrm{~h}$, and study participants were instructed to remain still with the forearm extended during each BP reading. Awake and night-time periods were defined 07:00 to 22:00, 22:01 to 06:59, repetitively. ABP recordings with less than $70 \%$ usable $\mathrm{BP}$ readings were excluded. All valid awake and nighttime ABP readings were averaged to provide a single awake and nighttime $A B P$ value per study participant.

For office BP and AOBP, we repeated BP measurement after and before see a doctor with same method. We illustrated BP measurement pathway (Fig. 1).

For identifying target organ damage, we evaluated left ventricular hypertrophy, pulse wave velocity and microalbuminuria. Left ventricular hypertrophy (LVH) was defined by the increased left ventricular mass index (LVMI) in transthoracic echocardiography. (LVMI >

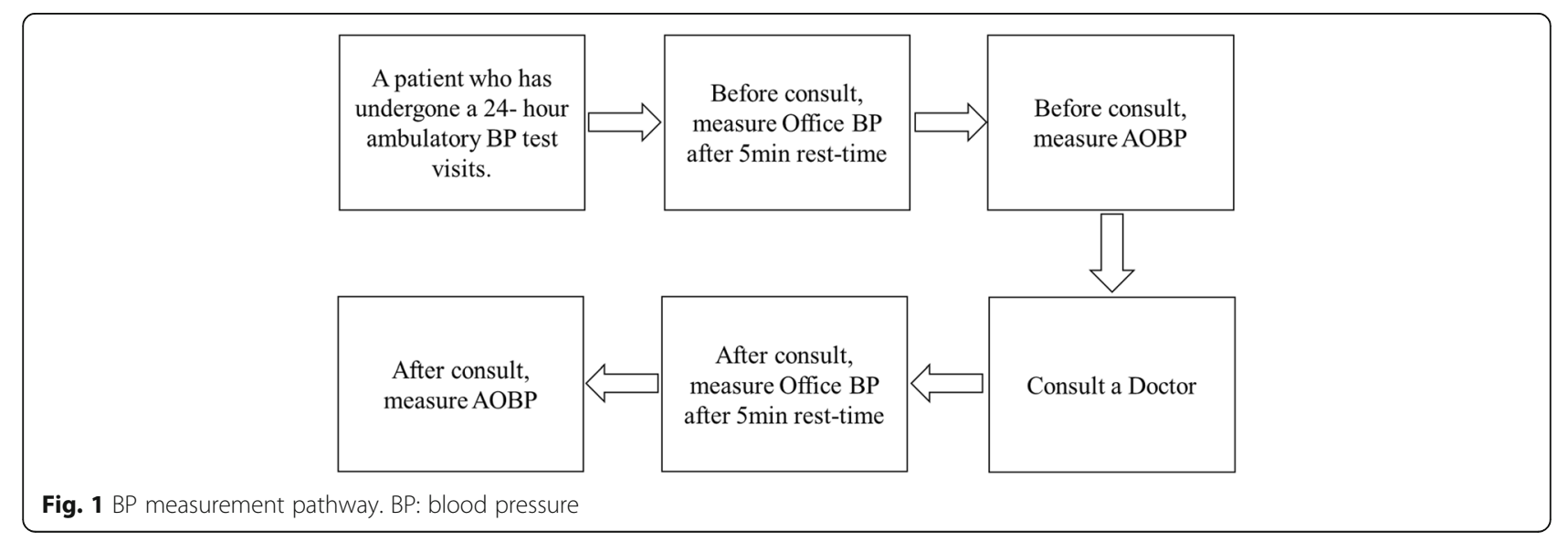


$115 \mathrm{~g} / \mathrm{m} 2$ in men and LVMI > $95 \mathrm{~g} / \mathrm{m} 2$ in women), Pulse Wave Velocity (PWV) was measured by pulse waveform analyzer. (Vp-1000 plus, Omron, Japan), Urine Albuminto-creatinine ratio (A/C ratio) was measured by a spot urine sample.

\section{Statistics}

Continuous variables are reported as mean \pm standard deviation (SD). Frequencies are given as percentages. Differences between mean systolic and diastolic AOBP values and heart rate (HR) were assessed using paired $t$ tests for "white coat effect" measurements. Similarly, differences between mean systolic and diastolic AOBP and 24-hour $\mathrm{BP}$ values were also assessed using $\mathrm{t}$ tests. We compared agreement between BP measurements in two ways: We used the method of Bland and Altman with bias (defined as the mean value of the differences) and $95 \%$ limits of agreement with their confidence intervals. The analyses were performed using the software $\mathrm{R}$, version 3.2.2 ( $\mathrm{R}$ Foundation for Statistical Computing, Vienna, Austria).

\section{Results}

A total of eighty two consecutive hypertensives fulfilling the criteria for enrollment were included in the study, 46 men and 36 women, with a mean age of $62.6 \pm 13.7$ years. Their clinical characteristics are shown in Tables 1 and 2 .

Table 1 Clinical characteristics

\begin{tabular}{ll}
\hline Variables & $\mathbf{N}=\mathbf{8 2}$ pts (\%) \\
\hline Age, year & $62.6 \pm 13.7$ \\
Sex, male & $46(43.9)$ \\
Dyslipidemia & $43(52.4)$ \\
Chronic kidney disease & $11(13.4)$ \\
Diabetes mellitus & $21(25.9)$ \\
Heart failure & $4(5.4)$ \\
Stroke & $6(7.3)$ \\
Myocardial infarction & $6(7.3)$ \\
Hemoglobin, g/dL & $13.87 \pm 1.62$ \\
Platelet & $245.8 \pm 69.1$ \\
BUN, mg/dL & $15.7 \pm 5.0$ \\
Creatinine, mg/dL & $1.0 \pm 1.1$ \\
HemoglobinA1c, \% & $6.2 \pm 0.9$ \\
hs-CRP, mg/L & $1.0 \pm 1.1$ \\
Total cholesterol, mg/dL & $161.6 \pm 39.0$ \\
Triglyceride, mg/dL & $134.9 \pm 83.7$ \\
LDL-cholesterol, mg/dL & $86.2 \pm 35.0$ \\
A/C ratio & $48.2 \pm 99.5$ \\
\hline BUN Blood urea ntrog &
\end{tabular}

$B U N$ Blood urea nitrogen, $h s-C R P$ high sensitivity $C$ reactive protein, $L D L$ cholesterol Low density lipoprotein cholesterol, $A / C$ ratio Albumin to creatinine ratio
Table 2 Medication

\begin{tabular}{ll}
\hline Variables & $\mathbf{N = 8 2 ~ p t s ~ ( \% ) ~}$ \\
\hline Antiplatelet & $39(47.6)$ \\
Numbers of BP medication & $2.27 \pm 0.96$ \\
Calcium channel antagonist & $50(64.1)$ \\
ARB & $64(81.0)$ \\
ACE inhibitor & $1(1.3)$ \\
Beta blocker & $31(37.8)$ \\
Diuretics & $12(15.2)$ \\
Vasodilator & $3(3.8)$ \\
Alpha blocker & $7(9.3)$ \\
\hline
\end{tabular}

$B P$ Blood pressure, $A R B$ Angiotensin receptor blocker, ACE Angiotensin converting enzyme

Overall blood pressure values are shown in Table 3. Significant difference was observed for the mean systolic $\mathrm{BP}$ values when $\mathrm{BC} \mathrm{BP}$ and $\mathrm{AC} \mathrm{BP}$ were performed. $(135.4 \pm 16.9$ vs. $131.9 \pm 16.4 \mathrm{mmHg}, P=0.015)$ (Fig. $2 \mathrm{~A}$ ) However, there was no difference in the mean diastolic BP between BC BP and AC BP. (73.6 \pm 11.8 vs. $74.4 \pm$ $11.7 \mathrm{mmHg}, p=0.415$ ) (Fig. 2B). Furthermore, systolic $\mathrm{BC}$ AOBP after see a doctor exhibited a significant difference when compared to systolic AC AOBP values. (125.1 \pm 14.4 vs. $123.0 \pm 14.1 \mathrm{mmHg}, p=0.006)$ (Fig. $2 \mathrm{~A}$ ). In the diastolic AOBP values, there was also significant difference between $\mathrm{BC}$ AOBP and AC AOBP (72.0 \pm 10.5 vs. $71.0 \pm 9.8, \mathrm{mmHg} p=0.038)$ unlike $\mathrm{BC}$ and $\mathrm{AC}$ diastolic BP. (Fig. 2B) For clinical use of AC BP, we compared AC BP with BC AOBP. These difference were $6.33 \pm 13.01 \mathrm{mmHg}(p<0.001), 2.14 \pm 7.65 \mathrm{mmHg}(p=$ $0.023)$ in systolic BP and diastolic BP, respectively (Fig. $3 \mathrm{~A}, 3 \mathrm{~B}$ ).

When compare among all $\mathrm{BP}$ values, both systolic and diastolic AC AOBP was lowest $(p=0.001)$ representing resting state.

Bland-Altman plots for the comparison of the systolic $\mathrm{AC} \mathrm{BP}, \mathrm{BC} \mathrm{BP}$ and diastolic $\mathrm{AC} \mathrm{BP}, \mathrm{BC}$ BP with the systolic $24 \mathrm{~h}$ mean $\mathrm{ABP}$ are shown in Fig. $3 \mathrm{~A}, \mathrm{~B}$, respectively. Differences between $24 \mathrm{~h} \mathrm{ABP}$ and office $\mathrm{BP}$ were $10.61 \mathrm{mmHg}$ for $\mathrm{BC} \mathrm{BP}$ and $7.61 \mathrm{mmHg}$ for $\mathrm{AC} \mathrm{BP}$, respectively. AC BP showed consistently narrower than $\mathrm{BC} \mathrm{BP}$.

For BP variability analysis, we checked difference between $\mathrm{BC} \mathrm{BP}$ and $\mathrm{AC} \mathrm{BP}$ and defined as delta office $\mathrm{BP}$ and analyzed correlation between delta office $\mathrm{BP}$ and $24 \mathrm{~h}$ BP deviation. There was no significant association between delta office BP and $24 \mathrm{~h}$ BP variability $(p=0.389)$.

For further evaluation, we analyzed correlation coefficient between $24 \mathrm{~h} \mathrm{ABP}$ and $\mathrm{BC}$ BP, AC BP, BC AOBP, and AC AOBP. Their correlations are shown in Fig. $4 \mathrm{~A}$, B. AC systolic BP $(r=0.43)$ was most correlated with $24 \mathrm{~h}$ ABP among 4 systolic BP measurements. For 
Table 3 Mean blood pressure values

\begin{tabular}{|c|c|c|c|c|c|c|}
\hline Variables & BC BP & $A C B P$ & BC AOBP & AC AOBP & $24 \mathrm{~h} \mathrm{ABP}$ & $P$-value \\
\hline $\mathrm{SBP}, \mathrm{mmHg}$ & $135.37 \pm 16.90$ & $131.95 \pm 16.40$ & $125.17 \pm 14.41$ & $122.98 \pm 14.09$ & $124.54 \pm 10.63$ & 0.001 \\
\hline $\mathrm{DBP}, \mathrm{mmHg}$ & $73.75 \pm 11.85$ & $74.42 \pm 11.71$ & $71.99 \pm 10.49$ & $70.99 \pm 9.83$ & $75.17 \pm 6.50$ & 0.001 \\
\hline h, bpm & & & $72.2 \pm 11.0$ & $70.7 \pm 10.6$ & & 0.063 \\
\hline
\end{tabular}

$B C$ Before consult, $A C$ After consult, $A O B P$ Automated office blood pressure, ABP Ambulatory blood pressure, SBP Systolic blood pressure, DBP Diastolic blood pressure, $H R$ Heart rate, $b p m$ beat per minute

diastolic BP, AC AOBP $(r=0.6)$ was most correlated with $24 \mathrm{~h}$ ABP among 4 diastolic measurements.

We defined white coat effect as blood pressure difference $>20 \mathrm{mmHg}$ using before and after office BP. we compared clinical values including left ventricular hypertrophy, pulse wave velocity and Urine $\mathrm{A} / \mathrm{C}$ ratio between patients with white coat effect and without white coat effect. However, there were no differences in the clinical values for assessing prognostic impact except urine $\mathrm{A} / \mathrm{C}$ ratio (Table 4).

Lastly, we compared BC and AC BP difference between men and women. There was no significant difference in BC SBP $(133.4 \pm 15.3$ vs. $137.8 \pm 18.6 \mathrm{mmHg}$, $p=0.269)$, AC SBP $(129.2 \pm 15.4$ vs. $135.4 \pm 17.1 \mathrm{mmHg}$, $p=0.101)$ and $\mathrm{BC}$ and $\mathrm{AC} \mathrm{BP}$ differences $(3.9 \pm 12.0$ vs. $2.2 \pm 10.8 \mathrm{mmHg}, p=0.523$ ) between men and women.

\section{Discussion}

To the best of our knowledge, this is first study to simultaneously compare BP values between before and after seeing a doctor for reducing white coat effect and examined for any differences in the mean AOBP when these readings were obtained before and after office consult. We also compared the office BP and AOBP values with $24 \mathrm{~h} \mathrm{ABP}$, which is generally accepted as a more sensitive risk predictor than office $\mathrm{BP}$ of $\mathrm{CV}$ events, in order to investigate any differences between AOBP and $24 \mathrm{~h}$ ABP values $[8,9]$.

Our findings showed that based on the automated BP measurement device, AC systolic BP was lower when readings with after seeing a doctor were taken. Furthermore, AC systolic AOBP had further lower in the similar situation. The mild association between AC BP and $24 \mathrm{~h}$ $A B P$ values was observed and the value was higher than other BP values. So, it should be highlighted that AC BP measurement should be considered as alternative routine practice.

The overall prevalence of white coat hypertension in the general population is estimated to be approximately $10-15 \%$, and it amounts to $30 \%$ in patients with increased clinic BP recordings [10]. White coat hypertension is more frequent in women, non-smokers, and
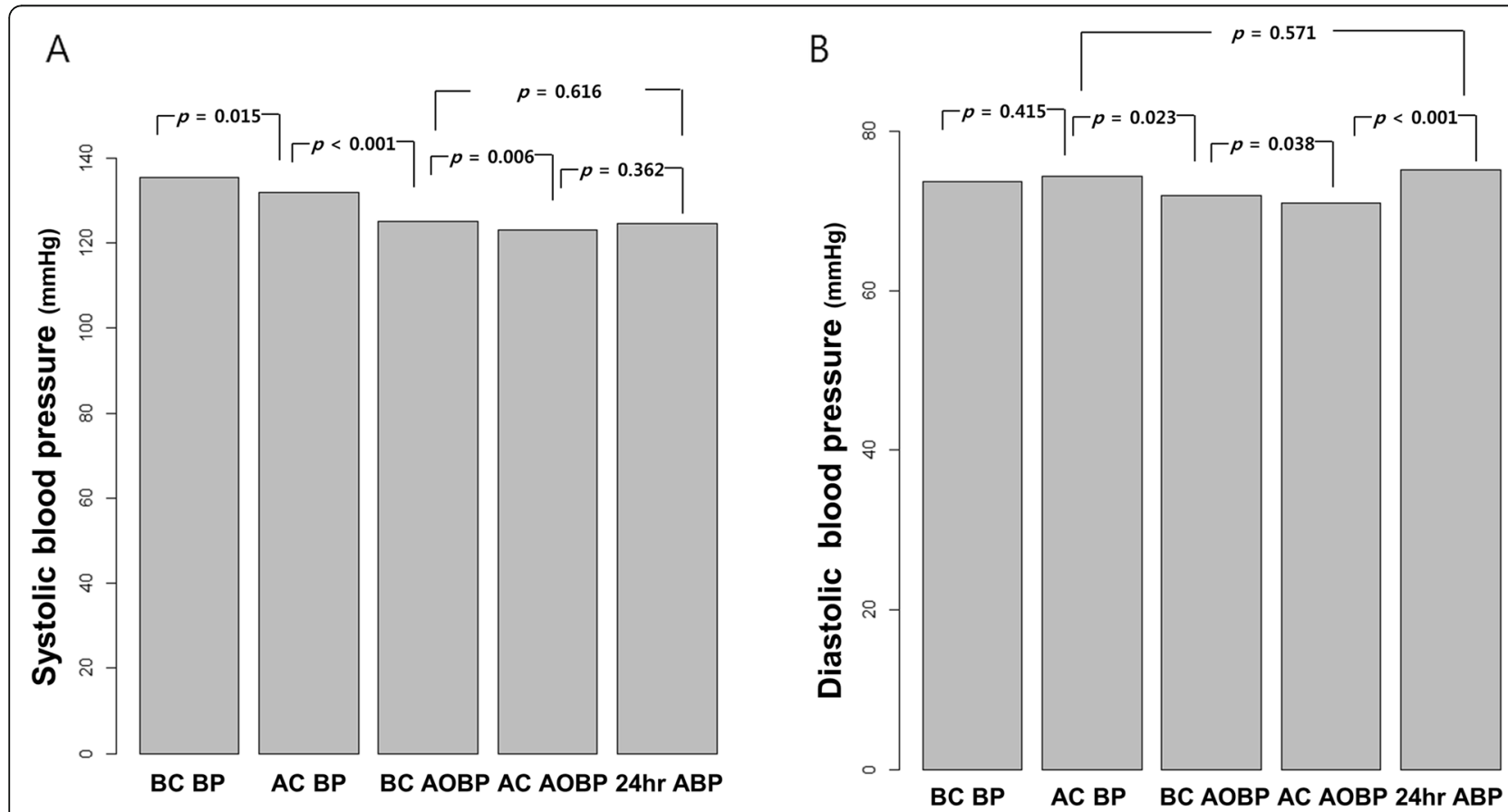

Fig. 2 Comparison among office, automated blood pressure, and $24 \mathrm{~h}$ ambulatory blood pressure. Systolic BP comparison (A), Diastolic BP comparison (B). BC; before consult, BP; blood pressure, AC; after consult, AOBP; automated office blood pressure, ABP; ambulatory blood pressure 

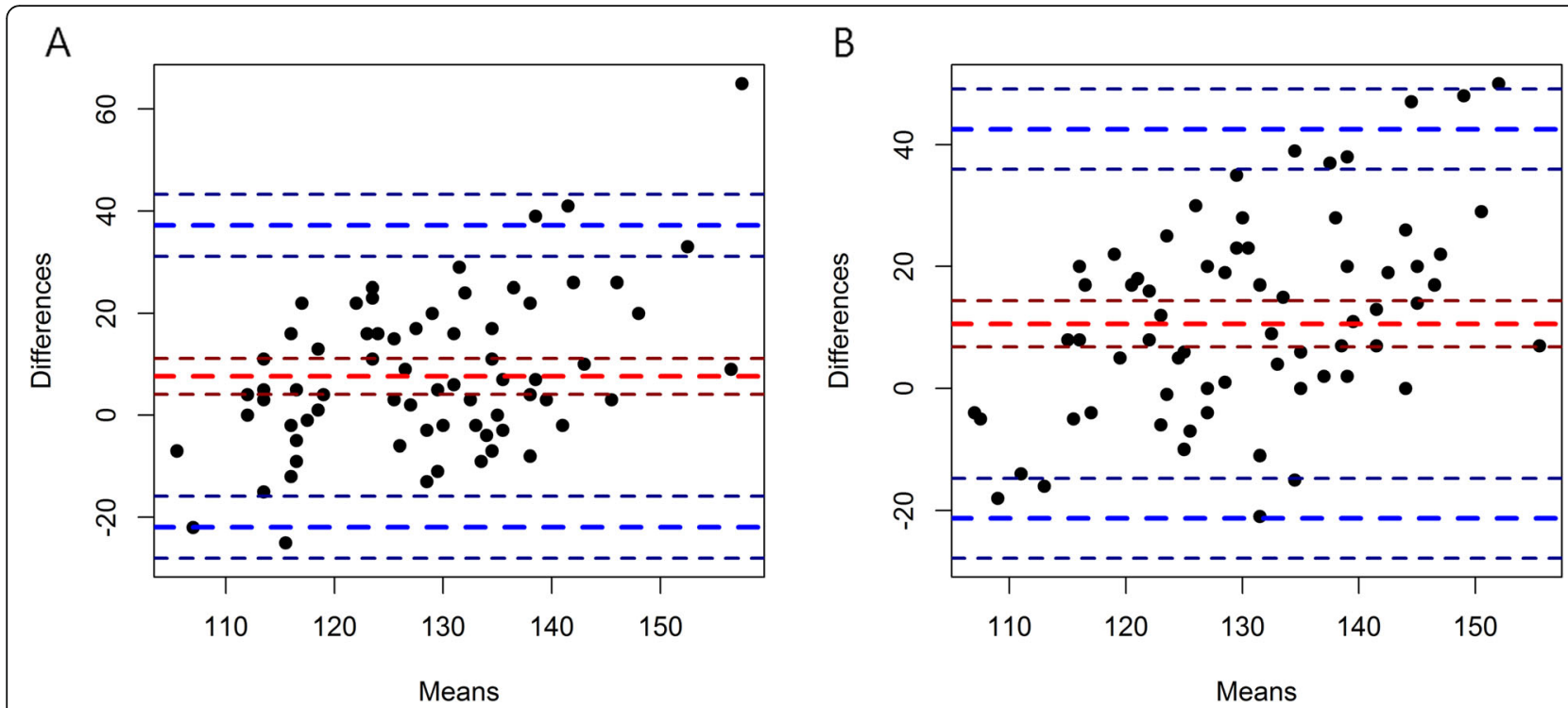

Fig. 3 Bland-Altman plot comparing mean after-consult systolic blood pressure (A), before-consult systolic blood pressure (B) with $24 \mathrm{~h}$ ambulatory blood pressure $(\mathrm{mmHg})$. AC; after consult, BC; before consult. Red dashed lines, mean bias; Blue dashed lines, $95 \%$ limits of agreement

patients with low clinic BP and smaller left ventricular mass at echocardiography [11]. Although the prevalence of white coat effect in the hypertension treatment during follow up period is not exactly known, it might be similar with that of white-coat hypertension. In addition, it is hard to take a sufficient rest before BP measurement in South Korea because both patients and physicians are pressed for office consultation time.

In our study, white coat effect was about $9.8 \%$ when we defined as $20 \mathrm{mmHg}$ difference between $\mathrm{BC}$ and $\mathrm{AC}$ systolic BP. So, AC BP that we measured BP after consult is fit to take a sufficient time and reduce white coat effect.

Recently, a study was performed for reducing white coat effect [12]. Emmanuel et al. examined the difference in AOBP readings, with and without 5 min of rest prior to three readings recorded at 1 -min intervals. In that study, systolic AOBP can be initially checked without any preceding rest and if readings are normal can be accepted. However, when AOBP is $\geq 130 \mathrm{~mm} \mathrm{Hg}$,

\begin{tabular}{|c|c|c|c|c|c|c|c|c|c|c|c|c|}
\hline$A$ & 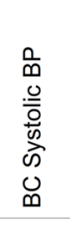 & $\begin{array}{l}\frac{0}{0} \\
\text { o } \\
\frac{0}{0} \\
\text { wn } \\
\omega \\
0 \\
0\end{array}$ & 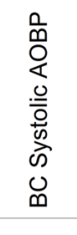 & $\begin{array}{l}0 \\
0 \\
0 \\
\frac{0}{0} \\
\frac{0}{0} \\
\frac{0}{w} \\
0 \\
0 \\
0\end{array}$ & 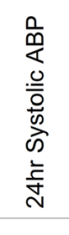 & B & 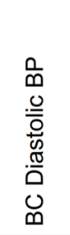 & 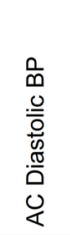 & 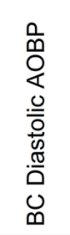 & 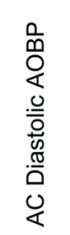 & 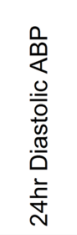 & \\
\hline BC Systolic BP & 1 & 0.75 & 0.62 & 0.51 & 0.38 & BC Diastolic BP & 1 & 0.82 & 0.77 & 0.73 & 0.51 & 0.8 \\
\hline AC Systolic BP & 0.75 & 1 & 0.62 & 0.58 & 0.43 & AC Diastolic BP & 0.82 & 1 & 0.75 & 0.76 & 0.54 & \\
\hline BC Systolic AOBP & 0.62 & 0.62 & 1 & 0.87 & 0.41 & BC Diastolic AOBP & 0.77 & 0.75 & 1 & 0.91 & 0.58 & 0 \\
\hline AC Systolic AOBP & 0.51 & 0.58 & 0.87 & 1 & 0.34 & AC Diastolic AOBP & 0.73 & 0.76 & 0.91 & 1 & 0.6 & -0.4 \\
\hline 24hr Systolic ABP & 0.38 & 0.43 & 0.41 & 0.34 & 1 & 24hr Diastolic ABP & 0.51 & 0.54 & 0.58 & 0.6 & 1 & -0.8 \\
\hline
\end{tabular}


Table 4 Comparison clinical values between patients with white coat effect and without white coat effect

\begin{tabular}{llll}
\hline & $\begin{array}{l}\text { White coat effect(+) } \\
\boldsymbol{N}=\mathbf{8}\end{array}$ & $\begin{array}{l}\text { White coat effect(-) } \\
\boldsymbol{N}=\mathbf{7 4}\end{array}$ & $\boldsymbol{P}$ value \\
\hline LVH & $2(28.57 \%)$ & $4(4.76 \%)$ & 0.258 \\
PWV, cm/sec & $1547.17 \pm 820.34$ & $1607.58 \pm 366.79$ & 0.865 \\
A/C ratio & $12.66 \pm 3.66$ & $50.91 \pm 103.90$ & 0.007 \\
\hline
\end{tabular}

LVH Left ventricular hypertrophy, PWV Pulse wave velocity, A/C ratio Urine albumin to creatinine ratio

measurements should be rechecked with 5 min of rest. So, it has limitation for daily routine practice.

We still used $24 \mathrm{~h} \mathrm{ABP}$ as reference standard. A recent meta-analysis showed that due to the significant heterogeneity it is believed that use of the AOBP should not replace daytime ABP.

Interestingly, it should be highlighted that $\mathrm{AC}$ systolic AOBP value was lower than $24 \mathrm{~h} \mathrm{ABP}$. Our findings are inconsistent with those of others $[13,14]$ that clinic BP values were higher than daytime $\mathrm{ABP}$ values in the higher range of $\mathrm{BP}$ distribution. We suggested even AOBP might have white coat effect and AC AOBP could reflect most comfortable resting $\mathrm{BP}$ state.

This study has several limitations. First, it should be mentioned that the entrance of the study personnel into the examination room before recording before or afterconsult BP with 5 min resting cannot completely eliminate noisy circumstance. However, we believe that situation reflected more real clinical practice. Second, the relatively small size of the study population may limit generalization of study results. Third, we could not check the long-term prognosis because we concentrated on method of BP measurement. We will identify the adverse event in the near future.

\section{Conclusions}

In our study, AC AOBP was most lowest representing resting state. Overall $\mathrm{AC} B \mathrm{BP}$ including routine $\mathrm{BP}$ and AOBP was lower than $\mathrm{BC}$ BP. Based on the present results, although $\mathrm{AC} B \mathrm{~B}$ was higher than $\mathrm{BC} \mathrm{AOBP}$, it might be used as alternative measurement in the routine clinical practice for reducing white coat effect.

\section{Acknowledgements}

We thank the heart and vascular lab. team of our hospital for their assistance in conducting the study.

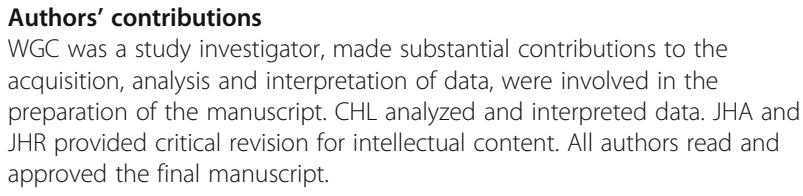

WGC was a study investigator, made substantial contributions to the acquisition, analysis and interpretation of data, were involved in the preparation of the manuscript. CHL analyzed and interpreted data. JHA and $J H R$ provided critical revision for intellectual content. All authors read and approved the final manuscript.

\section{Funding}

This work was supported by the Korean Society of Hypertension (KSH grants KSH-R-2018-03).

\section{Availability of data and materials}

The datasets used and/or analyzed during the current study are available from the corresponding author on reasonable request.

\section{Declarations}

Ethics approval and consent to participate

The study was conducted in accordance with the ethical principles that have their origins in the Declaration of Helsinki. All enrolled patients provided written informed consent prior to undergoing any study-related procedure. The study protocol and relevant documentation were approved by from the Institutional Review Board of Konkuk University Chungju Hospital, Chungju, Korea (IRB No: KUCH 2019-09-030).

\section{Consent for publication}

Not applicable.

\section{Competing interests}

$\mathrm{CHL}, J H A, J H R$, and WGC declare that they have no competing interests.

\section{Author details}

${ }^{1}$ Cardiology, Konkuk University Chungju Hospital, Chungju, South Korea.

${ }^{2}$ Internal medicine, School of Medicine, Konkuk University, 82,

Gugwon-dearo, Chungju, Chungbuk 27376 Chungju, South Korea.

Received: 10 December 2020 Accepted: 2 June 2021

Published online: 01 August 2021

\section{References}

1. Franklin SS. Cardiovascular risks related to increased diastolic, systolic and pulse pressure. An epidemiologist's point of view. Pathol Biol. 1999;47(6): 594-603.

2. Agarwal R. Longitudinal Study of Left Ventricular Mass Growth: Comparative Study of Clinic and Ambulatory Systolic Blood Pressure in Chronic Kidney Disease. Hypertension. 2016;67(4):710-6.

3. Paul K, Whelton RM, Carey, Wilbert S, Aronow DE, Casey Jr, Karen J, Collins C, Himmelfarb D, et al 2017 ACC/AHA/AAPA/ABC/ACPM/AGS/APhA/ASH/ ASPC/NMA/PCNA Guideline for the Prevention, Detection, Evaluation, and Management of High Blood Pressure in Adults: Executive Summary: A Report of the American College of Cardiology/American Heart Association Task Force on Clinical Practice Guidelines. J Am Soc Hypertens, 2018. 12(8): 579.e1-579.e73.

4. Bryan Williams G, Mancia W, Spiering EA, Rosei M, Azizi M, Burnier, et al. 2018 ESC/ESH Guidelines for the management of arterial hypertension. Eur Heart J. 2018:39(33):3021-104.

5. Martin G, Myers M, Godwin M, Dawes A, Kiss SW, Tobe, Janusz Kaczorowskiet. Measurement of blood pressure in the office: recognizing the problem and proposing the solution. Hypertension. 2010;55(2):195-200.

6. Myers MG, Valdivieso M, Kiss A. Consistent relationship between automated office blood pressure recorded in different settings. Blood Press Monit. 2009; 14(3):108-11.

7. Myers MG. Automated blood pressure measurement in routine clinical practice. Blood Press Monit. 2006;11(2):59-62.

8. José R, Banegas, Luis M, Ruilope A, de la Sierra E, Vinyoles, Manuel Gorostidi, Juan J, de la Cruz, et al. Relationship between Clinic and Ambulatory BloodPressure Measurements and Mortality. N Engl J Med. 2018;378(16):1509-20.

9. George C, Roush RH, Fagard GF, Salles SD, Pierdomenico G, Reboldi P, Verdecchia, et al. Prognostic impact from clinic, daytime, and night-time systolic blood pressure in nine cohorts of 13,844 patients with hypertension. J Hypertens. 2014;32(12):2332-40.

10. Fagard RH, Cornelissen VA. Incidence of cardiovascular events in white-coat, masked and sustained hypertension versus true normotension: a metaanalysis. J Hypertens. 2007;25(11):2193-8.

11. Verdecchia P, Palatini P, Schillaci G, Mormino P, Porcellati C, Pessina AC. Independent predictors of isolated clinic ('white-coat') hypertension. J Hypertens. 2001;19(6):1015-20.

12. Andreadis EA, Geladari CV, Angelopoulos ET. Automated office blood pressure measurements obtained with and without preceding rest are associated with awake ambulatory blood pressure. J Clin Hypertens. 2020; 22(1):32-8. 
13. Mancia G, Sega R, Bravi C, De Vito G, Valagussa F, Cesana G, Zanchetti A Ambulatory blood pressure normality: results from the PAMELA study. J Hypertens. 1995;13:1377-90.

14. Giuseppe Mancia R, Facchetti G, Parati A, Zanchetti. Effect of long-term antihypertensive treatment on white-coat hypertension. Hypertension. 2014; 64(6):1388-98.

\section{Publisher's Note}

Springer Nature remains neutral with regard to jurisdictional claims in published maps and institutional affiliations.

Ready to submit your research? Choose BMC and benefit from:

- fast, convenient online submission

- thorough peer review by experienced researchers in your field

- rapid publication on acceptance

- support for research data, including large and complex data types

- gold Open Access which fosters wider collaboration and increased citations

- maximum visibility for your research: over $100 \mathrm{M}$ website views per year

At BMC, research is always in progress.

Learn more biomedcentral.com/submissions 